\title{
A REVIEW OF CANDU FEEDER WALL THINNING
}

\author{
HAN-SUB CHUNG \\ Chief Researcher, Nuclear Power Generation Lab, Korea Electric Power Research Institute \\ 65 Munji-Ro, Yusung-Gu, Daejeon, 305-380, Korea \\ *Corresponding author. E-mail : hschung@kepri.re.kr \\ Received April 01, 2010 \\ Accepted for Publication July 24, 2010
}

Flow Accelerated Corrosion is an active degradation mechanism of CANDU feeder. The tight bend downstream to Gray loc weld connection, close to reactor face, suffers significant wall thinning by FAC. Extensive in-service inspection of feeder wall thinning is very difficult because of the intense radiation field, complex geometry, and space restrictions. Development of a knowledge-based inspection program is important in order to guarantee that adequate wall thickness is maintained throughout the whole life of feeder. Research results and plant experiences are reviewed, and the plant inspection databases from Wolsong Units One to Four are analyzed in order to support developing such a knowledge-based inspection program. The initial thickness before wall thinning is highly non-uniform because of bending during manufacturing stage, and the thinning rate is non-uniform because of the mass transfer coefficient distributed non-uniformly depending on local hydraulics. It is obvious that the knowledge-based feeder inspection program should focus on both fastest thinning locations and thinnest locations. The feeder wall thinning rate is found to be correlated proportionately with QV of each channel. A statistical model is proposed to assess the remaining life of each feeder using the QV correlation and the measured thicknesses. W-1 feeder suffered significant thinning so that the shortest remaining life barely exceeded one year at the end of operation before replacement. W-2 feeder showed far slower thinning than W-1 feeder despite the faster coolant flow. It is believed that slower thinning in W-2 is because of higher chromium content in the carbon steel feeder material. The average $\mathrm{Cr}$ content of W-2 feeder is $0.051 \%$, while that value is $0.02 \%$ for $\mathrm{W}-1$ feeder. It is to be noted that FAC is reduced substantially even though the $\mathrm{Cr}$ content of W-2 feeder is still very low.

KEYWORDS : CANDU, Feeder, Flow Accelerated Corrosion, Carbon Steel, Wall Thinning, Remaining Life

\section{INTRODUCTION}

The primary heat transport system of CANDU circulates the reactor coolant between the reactor and the steam generators. Each CANDU reactor in the Wolsong station is composed of 380 pressure tubes containing nuclear fuel elements, and each pressure tube is connected to the header on the way to or from the steam generator through feeders. Hence, there are 380 feeders, each connected to the reactor inlet and outlet. The nominal sizes of the feeders are 1.5, 2, 2.5, 3, and 3.5inches. The feeder piping material is ASTM A-106 carbon steel. The feeder is weld connected to the Gray loc, which is attached to the end fitting of each pressure tube. Because of the geometric restrictions near the reactor inlet and outlet faces, the feeders are bent tightly close to the weld connection. The bend radius is as small as one and a half times the nominal diameter. Some bends are double bent, such as the first and second bend; the others are single bent. There are bends away from the reactor face, whose bend radius is equal or greater than four times the nominal diameter. The bend close to the reactor face is called a tight bend.

Each channel has different operation conditions, such as thermal output, temperature, and coolant flow. The temperature of the coolant entering the reactor is distributed around $265^{\circ} \mathrm{C}$, and that exiting the reactor is distributed around $310^{\circ} \mathrm{C}$. The internal pressure of the feeder is $11 \mathrm{MPa}$ at the inlet location, and $10.3 \mathrm{MPa}$ at the outlet location. The reactor inlet coolant is sub-cooled water, but the outlet coolant may contain some fraction of void, less than $5 \%$ at most, depending on channel specific operation conditions. The tight bend location of the outlet feeder suffers wall thinning caused by Flow Accelerated Corrosion (FAC). High temperature and fast coolant flow through the tight bend are the major causes of FAC. There are two nominal sizes of feeder in the outlet tight bend, 2 and 2.5 inches. The bend geometry is shown schematically in Fig. 1 . Geometry types of the outlet feeder are summarized in Table 1.

Excessive thinning reduces the pressure retaining capability of piping so that the minimum allowable thickness of the feeder should be maintained throughout the life of 
the feeder. Feeder wall thinning should be monitored by in-service inspection. A knowledge-based inspection strategy needs to be developed since the combination of

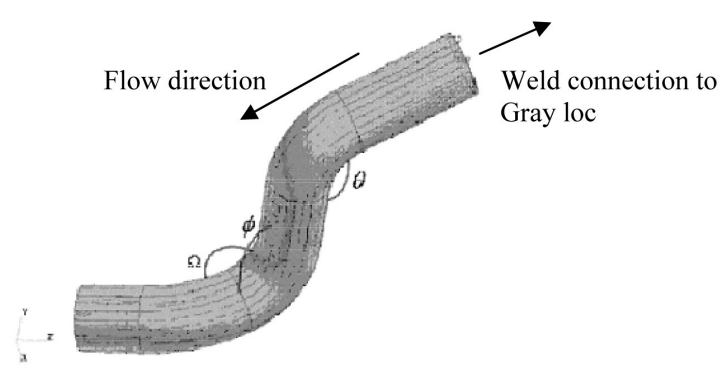

Fig. 1. First Bend and Second Bend Geometry high radiation field and geometric restrictions near the tight bend location makes extensive inspection very difficult. The current understanding and plant experiences are reviewed, and inspection databases of Wolsong Units One to Four are analyzed in order to support the development of a knowledge-based inspection strategy for feeder wall thinning.

\section{BACKGROUND OF FEEDER WALL THINNING}

\subsection{Flow Accelerated Corrosion}

FAC is a type of corrosion of carbon steel, accelerated by fast flowing coolant at high temperature and under reducing environment. FAC is distinguished from erosion

Table 1. Geometry of Outlet Feeder Tight Bends

\begin{tabular}{|c|c|c|c|c|c|c|c|c|}
\hline Bend Type & $\begin{array}{l}\text { Number of } \\
\text { Feeders }\end{array}$ & $\begin{array}{l}\text { Outside Dia. } \\
(\mathrm{mm})\end{array}$ & $\begin{array}{l}\text { 1st Bend } \\
\text { Angle } \\
\text { (degree) }\end{array}$ & $\begin{array}{l}\text { 2nd bend } \\
\text { Angle } \\
\text { (degree) }\end{array}$ & $\begin{array}{c}\text { Distance } \\
\text { from Hub to } \\
1^{\text {st }} \text { bend }(\mathrm{mm})\end{array}$ & \begin{tabular}{|c|} 
Distance \\
between $1 \mathrm{st}$ \\
bend and $2 \mathrm{nd}$ \\
bend $(\mathrm{mm})$
\end{tabular} & $\begin{array}{c}\text { Twisted } \\
\text { angle, } 1^{\text {st }} / 2^{\text {nd }} \\
\text { bend (degree) }\end{array}$ & $\begin{array}{l}\text { Inner Dia. } \\
(\mathrm{mm})\end{array}$ \\
\hline 1 & 2 & \multirow{10}{*}{73.025} & 32.717 & 32.717 & 16.51 & 38.1 & 180 & \multirow{10}{*}{59.004} \\
\hline 2 & 8 & & 42.833 & 30.150 & 48.006 & 38.1 & 128.8 & \\
\hline 3 & 12 & & 42.833 & 30.150 & 48.006 & 38.1 & 12.8 .8 & \\
\hline $4 \mathrm{~A}$ & 20 & & 73.133 & 70.000 & 15.24 & 24.89 & 146.38 & \\
\hline $4 \mathrm{~B}$ & 18 & & 73.133 & 70.000 & 15.24 & 38.35 & 146.38 & \\
\hline $4 \mathrm{C}$ & 16 & & 73.133 & 70.000 & 15.24 & 146.30 & 146.38 & \\
\hline $5 \mathrm{~A}$ & 12 & & 73.133 & 70.000 & 15.24 & 24.89 & 146.38 & \\
\hline $5 \mathrm{~B}$ & 16 & & 73.133 & 70.000 & 15.24 & 38.35 & 146.38 & \\
\hline $5 \mathrm{C}$ & 22 & & 73.133 & 70.000 & 15.24 & 146.30 & 146.38 & \\
\hline 6 & 194 & & 73.133 & $*$ & 15.24 & $*$ & $*$ & \\
\hline 7 & 20 & \multirow{10}{*}{60.325} & 32.717 & 32.717 & 23.622 & 49.28 & 180 & \multirow{10}{*}{49.25} \\
\hline 8 & 8 & & 42.833 & 30.150 & 56.896 & 50.8 & 128.8 & \\
\hline 9 & 6 & & 42.833 & 30.150 & 56.896 & 50.8 & 12.8 .8 & \\
\hline $10 \mathrm{~A}$ & 4 & & 73.133 & 70.000 & 30.48 & 52.32 & 146.38 & \\
\hline $10 \mathrm{~B}$ & 4 & & 73.133 & 70.000 & 30.48 & 65.79 & 146.38 & \\
\hline $10 \mathrm{C}$ & 2 & & 73.133 & 70.000 & 30.48 & 173.74 & 146.38 & \\
\hline $11 \mathrm{~A}$ & 2 & & 73.133 & 70.000 & 30.48 & 52.32 & 146.38 & \\
\hline $11 \mathrm{~B}$ & 2 & & 73.133 & 70.000 & 30.48 & 65.79 & 146.38 & \\
\hline $11 \mathrm{C}$ & 4 & & 73.133 & 70.000 & 30.48 & 173.74 & 146.38 & \\
\hline 12 & 8 & & 73.133 & $*$ & 30.48 & $*$ & $*$ & \\
\hline Total & 380 & & & & & & & \\
\hline
\end{tabular}

*Type 6 and 12 do not have second bend. 
since $\mathrm{FAC}$ is the chemical dissolution of iron into ferrous ions $\left(\mathrm{Fe}^{2+}\right)$ while erosion is caused by mechanical damage. The accelerating role of the fast flow is to enhance the mass transfer of ferrous ions at the iron oxide/water interface into the bulk of flowing water. FAC is widespread among carbon steel piping in power plants. An extensive and comprehensive review of the underlying mechanisms and the plant experiences of FAC in power plants has been published by the Electric Power Research Institute [1]. FAC has been an extensively active degradation mechanism of the carbon steel secondary side piping of nuclear power reactors. Piping failure incidents caused by excessive thinning have been reported. The ferrous ions dissolved by FAC enter into the steam generator and are deposited there as sludge, mainly composed of magnetite $\left(\mathrm{Fe}_{3} \mathrm{O}_{4}\right)$.

The thinning rate of the feeder, less than $0.13 \mathrm{~mm} /$ year at the fastest, is not as fast as that of the secondary piping of a PWR, which can be as high as a few mm/year. However, since the feeder is made of small bore piping with fairly low wall thickness, the lifetime accumulated thinning can lead to deteriorated structural integrity. The ferrous ions dissolved from the feeder by FAC precipitate as magnetite on the inside surface of the steam generator tubes, deteriorating the heat transfer capability [2 5].

The major factors affecting FAC may be divided into the chemistry factors and the hydraulics factors. The chemistry factors include material and aqueous chemistry. Chromium content of steel is a critical factor affecting resistance to FAC. Even a low concentration of chromium, as low as a few tenths of a percent, may for all practical purposes eliminate FAC. It is understood that small amount of chromium makes dense and protective oxide film. Oxygen content and $\mathrm{pH}$ are the major aqueous chemistry factors affecting FAC. A test program has indicated that very small amount of dissolved oxygen, as low as $1 \mathrm{ppb}$, may practically annihilate FAC [6]. The $\mathrm{pH}$ of water determines the solubility of magnetite in water. High solubility of magnetite accelerates FAC. The solubility of magnetite can be calculated using the famous Sweeton \& Baes equation, shown as equation (1) [7, 8].

$$
\begin{gathered}
\frac{1}{3} \mathrm{Fe}_{3} \mathrm{O}_{4}+(2-\mathrm{b}) \mathrm{H}^{+}+\frac{1}{3} \mathrm{H}_{2} \leftrightarrow \mathrm{Fe}(\mathrm{OH})_{\mathrm{b}}^{(2-\mathrm{b})-} \\
+\left(\frac{4}{3}-\mathrm{b}\right) \mathrm{H}_{2} \mathrm{O}
\end{gathered}
$$

Where $b=0$ to 3

The magnetite solubility as calculated by equation (1) explains the feeder thinning rate depending on $\mathrm{pH}$ [3 5]. The lower $\mathrm{pH}$ in the CANDU operation window, between 10.2 and $10.8 \mathrm{pHa}$, decreases the thinning rate. Equation (1) also indicates that the magnetite solubility depends on temperature, so that the solubility is higher in the rector outlet feeder, and lower in the inlet feeder. This explains why wall thinning is found only in the outlet feeder [3 5].
The hydraulic factors include flow velocity, geometry of piping, steam quality (or void fraction), and surface roughness. The hydraulic factors are important because they govern the local mass transfer coefficient. It is understood generally that the FAC rate is proportional to the mass transfer coefficient, as in equation (2).

$$
\mathrm{FAC} \text { rate }=\mathrm{k} \times\left(\mathrm{C}_{\mathrm{s}}-\mathrm{C}_{\infty}\right)
$$

k mass transfer coefficient $(\mathrm{m} / \mathrm{sec})$

Cs concentration of ferrous ions at the oxide/water interface

Co concentration of ferrous ions in the flowing bulk

\subsection{Thinnest Location}

The nominal thickness of 2 and $2.5 \mathrm{inch}$ feeder (Schedule 80) is 5.537 and $7.010 \mathrm{~mm}$. The minimum allowable wall thickness is calculated with ASME Boiler and Pressure Vessel Code Section III, equation NB-3642.1, as 2.61 and $3.16 \mathrm{~mm}$ for 2 and $2.5 \mathrm{inch}$ feeders. These are the minimum thicknesses required to sustain the integrity of the feeder against internal pressure. The maintenance
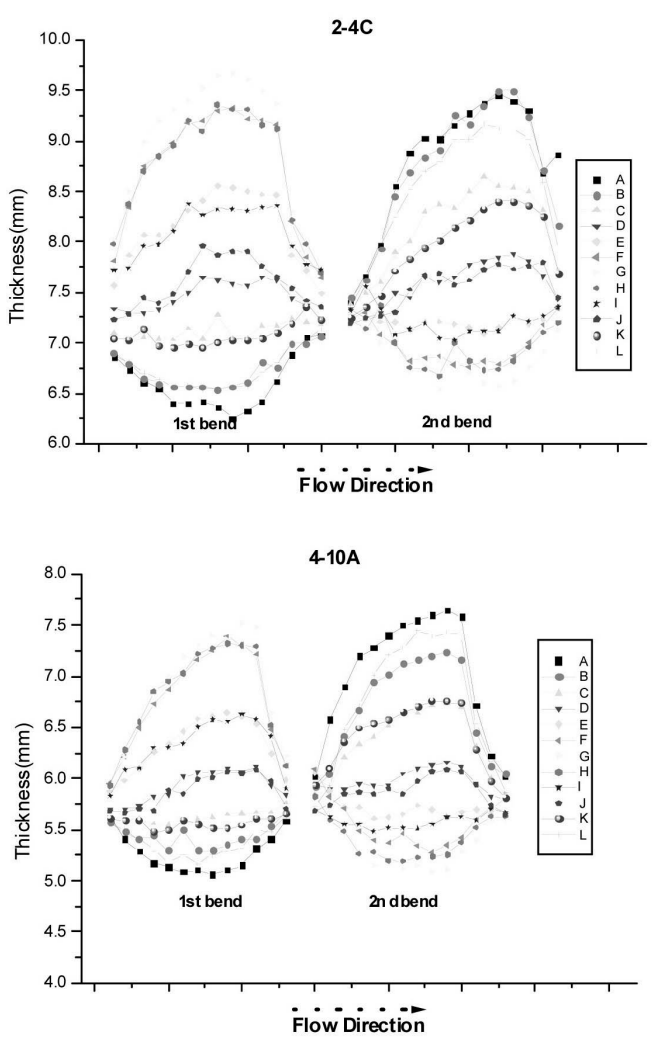

Fig. 2. Initial Wall Thickness Profiles After Bending (Type 4C \& 10A Bend) 
strategy against wall thinning is to inspect wall thickness of the feeder periodically to monitor wall thinning and to guarantee that the minimum allowable wall thickness is not violated during the operation life of the feeder. When a violation of the minimum allowable thickness is predicted, the feeder should be repaired. The initial thickness of each feeder, before wall thinning, is not evenly distributed. During bending in the manufacturing stage, extrados of the bend becomes thinner and the intrados becomes thicker than those factors in the straight pipe. Fig. 2 shows an example of wall thickness profile after bending. The wall thickness of the tight bend of the archive feeders was scanned by ultrasonic examination along with the flow direction at twelve evenly spaced circumferential locations. Considerable differences in thickness are noted depending on locations in the bends. Extrados is thinner than intrados by approximately $2.5 \sim 3 \mathrm{~mm}$. This is a significant difference considering that the annual thinning rate is less than $0.15 \mathrm{~mm}$ at most. It should be noted that the margin of the initial thinnest location is only $2.5 \sim 3 \mathrm{~mm}$ against the allowable minimum thickness. The smaller the nominal pipe size, the smaller the margin.

FAC is not evenly distributed throughout the bend. Turbulence develops when coolant escapes from the end fitting of the pressure tube and is connected to the feeder and passes through the tight radius bends. Computational fluid dynamics software may be a powerful tool to calculate the distribution of local mass transfer coefficient depending on the geometry and the location of the feeder. The plant in-service inspection database is another source of information regarding the distribution of FAC, depending on geometry and location. It is understood that the location of maximum mass transfer coefficient does not coincide with the initial thinnest location.

Since feeder wall thinning is very slow, mostly less than $0.1 \mathrm{~mm} /$ year, the extrados maintains the thinnest location until very late, if not until the end, of the operation life, so that the thinnest location may be different from the location of fastest thinning.

\subsection{In-Service Inspection}

Ultrasonic measurement of feeder wall thickness by in-service inspection is a challenging task because of the intense radiation field close to the reactor face and the complex geometry, combined with space restrictions. Feeder wall thinning emerged as an important safety issue of CANDU in the mid 1990s, and in-service inspection of the thickness of the tight bend feeder started from then. The early stage inspections focused only on measurement of wall thickness in the extrados of the first bend. The inspection was performed by manual ultrasonic test with point-to-point measurement. It was obvious that better inspection technology was needed in order to expand the inspection coverage into the extrados of the second bend, and then to the whole tight bend area and the downstream to the Gray loc weld. Currently, semi-automatic inspection tools are available, a 14 point bracelet for scanning thickness profile of whole tight bend location, and a Gray loc Area Inspection Tool for scanning thickness of area downstream to the weld. It is still a challenging task to measure thickness distribution of each feeder covering the whole set of bend locations.

Wolsong feeders have been inspected by manual ultrasonic examination. Extensive measurement data have

Table 2. Operation Conditions of W-1 \& 2 Outlet Feeders

\begin{tabular}{|c|c|c|c|c|c|}
\hline & & W-1, 2inch & $\mathrm{W}-1,2.5$ inch & W-2, 2inch & $\mathrm{W}-2,2.5 \mathrm{inch}$ \\
\hline \multirow{4}{*}{$\begin{array}{c}\text { Temperature } \\
\left({ }^{\circ} \mathrm{C}\right)\end{array}$} & average & 307.1 & 306.4 & 310.7 & 310.4 \\
\hline & maximum & 309.9 & 310.0 & 311.7 & 312.0 \\
\hline & minimum & 302.9 & 303.1 & 308.5 & 308.2 \\
\hline & standard deviation & 1.5 & 1.2 & 0.7 & 0.8 \\
\hline \multirow{4}{*}{$\begin{array}{l}\text { flow velocity } \\
\qquad(\mathrm{m} / \mathrm{sec})\end{array}$} & average & 9.70 & 11.59 & 10.90 & 12.49 \\
\hline & maximum & 11.66 & 13.65 & 13.50 & 14.56 \\
\hline & minimum & 7.58 & 6.08 & 7.78 & 6.85 \\
\hline & standard deviation & 1.02 & 1.71 & 1.38 & 1.63 \\
\hline \multirow{4}{*}{$\begin{array}{l}\text { mass flow } \\
(\mathrm{kg} / \mathrm{sec})\end{array}$} & average & 13.86 & 24.27 & 13.80 & 24.29 \\
\hline & maximum & 17.01 & 29.20 & 17.15 & 28.74 \\
\hline & minimum & 11.30 & 12.77 & 10.99 & 13.05 \\
\hline & standard deviation & 1.31 & 3.75 & 1.42 & 3.71 \\
\hline
\end{tabular}


been accumulated in the extrados of the first bends. Only a few sampled feeders have been inspected outside the extrados of the first bend.

\section{ANALYSIS OF PLANT INSPECTION DATABASE}

\subsection{W-1 Feeder Wall Thinning}

The first inspection on the tight bend of $\mathrm{W}-1$ feeders was performed in 1996 (11.56EFPYs), and the last inspection in 2007 (20.97EFPYs) before refurbishment. $\mathrm{W}-1$ feeder is replaced as a part of plant refurbishment, along with the pressure tube, one year after the last inspection. The inspection database between 1998 and 2007 was analyzed. The inspection data in 1996 and 1997 were abandoned since the measurement values were found to be less reliable.

It is empirically understood that the thinning rate of each feeder is proportional to QV. Q is the mass flow rate $(\mathrm{kg} / \mathrm{sec})$ and $\mathrm{V}$ is the linear flow rate $(\mathrm{m} / \mathrm{sec})$ of each channel. The operation condition of each channel is assessed from the accumulated operation data. One piece of data is selected randomly each month during normal operation between 6034 8028 full power days, and all the values are averaged to calculate the average operation condition. The operation condition of $\mathrm{W}-1$ and $\mathrm{W}-2$ are summarized as shown in Table 2 . W-2 operation data are averaged between 1512 4089 full power days. It should be noted that the temperature of the W-2 feeder is higher than that of the $\mathrm{W}-1$ feeders, so that the flow velocity is faster for $\mathrm{W}-2$ than for $\mathrm{W}-1$. The higher temperature means a higher void fraction, and thus faster flow under the same mass flow rate.
The minimum wall thickness as measured in each inservice inspection of the $\mathrm{W}-1$ feeder regressed with the EFPY as scaled by multiplying QV factor, as shown in Fig. 3. The QV factor is defined as 1 for the feeder with the highest $\mathrm{QV}$ value, and proportionately defined for other feeders. QV factors of 2inch and 2.5inch feeders are calculated separately. There are 3202.5 inch channels, and 602 inch channels. The minimum thickness is the thinnest value taken among the seven measurement points covering the extrados of each bend for each inspection. The slope in Fig. 3 may be considered as the average thinning rate calibrated by the QV factor. The statistical parameters from the regression are listed in the accompanying table. It should be noted that the y-axis intercept coincides with the estimated initial thickness for the 2.5 and 2inch feeders. The initial thickness at the extrados was estimated from the manufacturing databases to be $6.1 \sim 6.7 \mathrm{~mm}$ depending on bend angle for the $2.5 \mathrm{inch}$ feeder, and $5.1 \sim 5.2 \mathrm{~mm}$ for 2inch feeder. It is understood that the QV model gives reasonable regression.

It should be noted that the slope is considerably lower for the 2 inch feeder than for the 2.5 inch feeder. The ratio of the slopes is 1.38 . It is understood that 2.5 inch feeders are higher power channels, and thus flow faster. The ratio of average QV value of the $2.5 \mathrm{inch}$ feeder to the $2 \mathrm{inch}$ feeder is calculated to be 1.46 , as $\mathrm{Q}$ is corrected by dividing by the cross section area of each. The ratio of the average QV value, 1.46, coincides well with the ratio of slopes, 1.38 , indicating again that the QV model provides reasonable correlation.

Only a limited number of second bends have been inspected covering the extrados, while all the first bends

\begin{tabular}{|c|c|}
\hline $\mathrm{n}$ & 957 \\
\hline slope & -0.1104 \\
\hline intercept & 6.0064 \\
\hline $\begin{array}{c}\text { Standard } \\
\text { deviation }\end{array}$ & 0.2467 \\
\hline $\mathrm{R}^{2}$ & 0.7257 \\
\hline
\end{tabular}

(a) W-1, 2.5inch $1^{\text {st }}$ bend

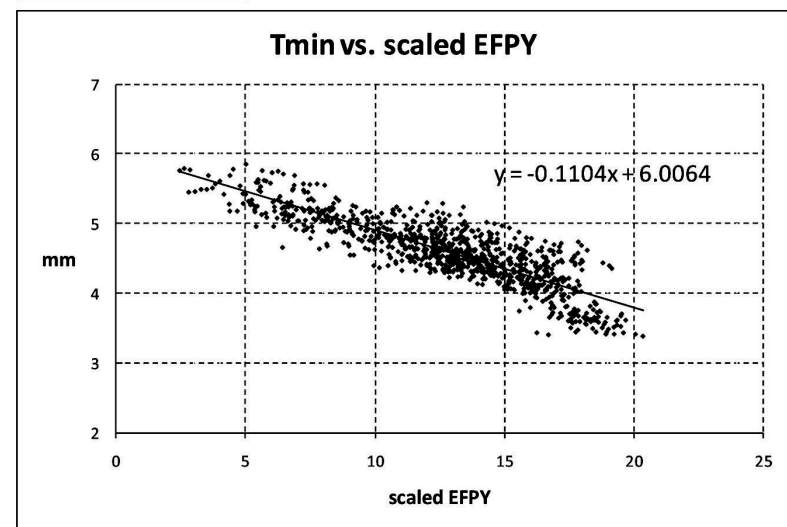

\begin{tabular}{|c|c|}
\hline $\mathrm{n}$ & 182 \\
\hline slope & -0.0800 \\
\hline intercept & 4.9055 \\
\hline $\begin{array}{c}\text { Standard } \\
\text { deviation }\end{array}$ & 0.1799 \\
\hline $\mathrm{R}^{2}$ & 0.6469 \\
\hline
\end{tabular}

(b) W-1, 2inch $2^{\text {nd }}$ bend

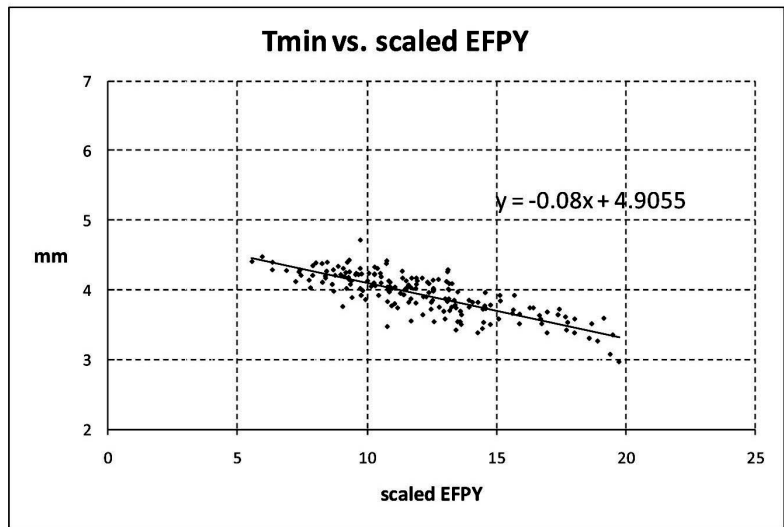

Fig. 3. Minimum Thicknesses vs. Scaled EFPY 
were inspected at least once. The minimum thicknesses at the second bend were compared with that at the first bend, as shown in Fig. 4. All data in Fig. 4 are from inspections in which both the first bend and the second bend were inspected at the same time. It is understood that there is no systematic difference between the first and second bends. Comparison of the thickness between the first bend and the second bend of the archive feeders, shown in Fig. 2, did not indicate any difference.

The remaining life can be assessed by the QV model. The algorithm for assessing the feeder specific remaining life is shown in Fig. 5. A line can be drawn with the same slope as shown in Fig. 4 from each measurement point, line (1) in Fig. 5, and the point where the line meets the critical thickness is the end of life. Lines (2) and (3) can be drawn in order to make a conservative assessment. Line (1) is the best estimation, line (2) adds thickness uncertainties, and line (3) adds slope uncertainties. Statistical parameters of the regression shown in Fig. 4 can be used to calculate

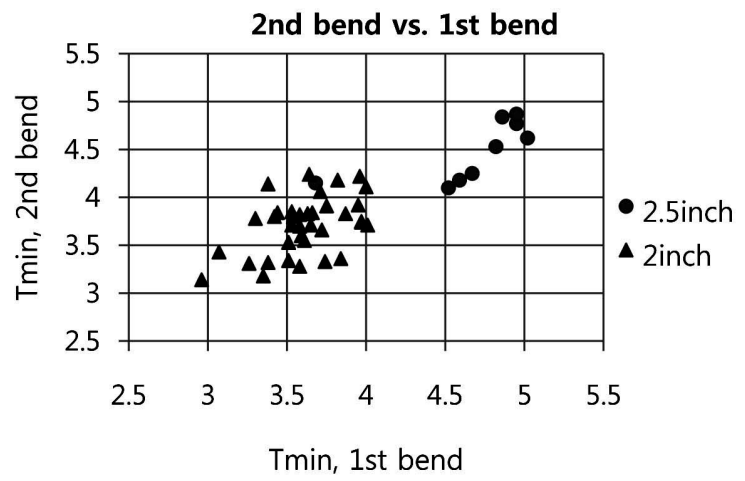

Fig. 4. Comparison of Minimum Thicknesses of the First Bend and Second Bend

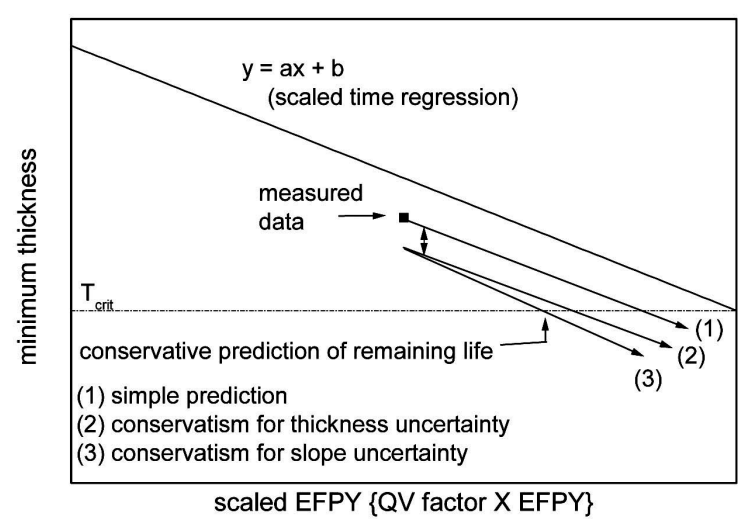

Fig. 5. Schematic Diagram of the Algorithm for Assessing the Remaining Life the percentile limit values, using the basic principles of statistics [9]. This method is useful to develop a guaranteed remaining life with adequate conservatism.

When the remaining life was calculated for each channel by the best estimation line, and the shortest remaining life was found to be 2.15 EFPYs from the time of last inspection, this barely exceeded one year at the end of operation before replacement. The thickness margin was almost exhausted. The shortest remaining life feeders are all 2.5 inch feeders. The shortest remaining life among 2inch feeders was 4.6EFPYs after the last inspection. It can be clearly seen that the 2.5 inch feeder suffers substantially faster wall thinning. It should be noted that the margin between the initial thickness against the minimum allowable thickness is smaller for the 2 inch feeder than for the 2.5 inch feeder.

\subsection{W-2 4 Feeder Wall Thinning}

W-2 feeder wall thinning databases were regressed in Fig. 6. The inspection data between 1998 (0.878EFPYs) and 2007 (9.92EFPYs) were analyzed. The regression is not as good as that for $\mathrm{W}-1$. The number of inspected feeders is far less than that for $\mathrm{W}-1$, and the total thinning is far shallower than that for W-1. Still, the y-intercept coincides well with the initial thickness. The straight pipe before bending was thicker for $\mathrm{W}-2 \sim 4$ than for $\mathrm{W}-1$ by around $0.3 \mathrm{~mm}$. The slope is far less than that of $\mathrm{W}-1$, only $41 \%$ for the $2.5 \mathrm{inch}$ feeder, indicating that the average feeder wall thinning rate is far slower for $\mathrm{W}-2$ than for W1. W-3 and 4 showed trends similar to that of W-2, even though the regression was poorer than that of $\mathrm{W}-2$.

\begin{tabular}{|c|c|}
\hline $\mathrm{n}$ & 266 \\
\hline slope & -0.0454 \\
\hline intercept & 6.3696 \\
\hline sde & 0.1298 \\
\hline $\mathrm{r} 2$ & 0.4273 \\
\hline
\end{tabular}

(a)

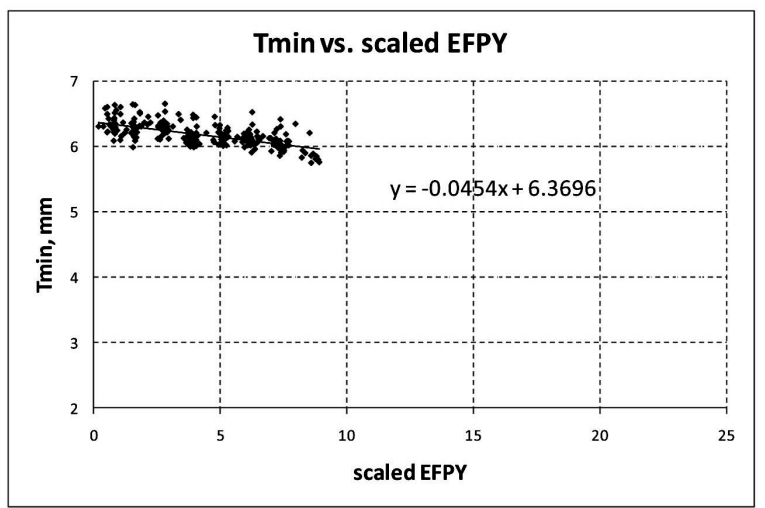

Fig. 6. Minimum Thicknesses vs. Scaled EFPY, W-2, 2.5inch $1^{\text {st }}$ Bend 


\section{DISCUSSION}

In-service inspection of the $\mathrm{W}-1$ feeder has focused mostly on the extrados of the first bend. All channels were inspected at least once, and many channels were inspected repeatedly. A small portion of sampled second bends and downstream to the Gray loc welds have been inspected. The W-1 feeder suffered extensive wall thinning so that the shortest remaining life was estimated to be only one year from the end of life before replacement. The analysis of the W-1 feeder inspection database provides valuable information, as summarized below.

- The thinning rate shows an empirical correlation proportional to the QV of each feeder.

- The 2.5inch feeder shows faster thinning and thus shorter remaining life than the 2 inch feeder, which can be understood by the QV correlation.

- There seems to be no systematic difference between the thinning rate of the first bend and the second bend. The amount of inspection data, however, may not be extensive enough to draw a firm conclusion.

It should be noted that the W-2 feeder shows a substantially slower thinning rate than that of the $\mathrm{W}-1$. Comparison of Figs. 3 and 6 indicates that the overall thinning rate of the $\mathrm{W}-2$ feeder is less than half that of the $\mathrm{W}-1$ feeder. It can be seen from Table 2 that the W-2 feeder operates at a higher temperature and thus a higher flow velocity than the $\mathrm{W}-1$ feeder. If only the operation condition is considered, the W-2 feeder should suffer faster thinning than the $\mathrm{W}-1$. This discrepancy needs to be explained. The difference of operation duration and feeder material may warrant further discussion.

W-1 inspection data are from the later portion of operation life, while W-2 inspection data are from the early portion of operation life. It is well understood that the FAC develops scallop patterns on the surface of the steel to increase surface roughness, and the increased roughness may be able to accelerate FAC by enhancing the mass transfer coefficient. Then, is the slower thinning rate of the W-2 feeder caused by the different portion of operating life? It is found not to be appropriate. Both Figs. 3 and 6 indicate that the $y$ intercept coincides well with the initial thickness, indicating a consistent thinning rate throughout the life. Canadian experiences also indicate that the thinning rate was maintained as consistent throughout the life of the plants [2].

The chemistry of the feeders was reviewed from the plant database in order to see if the W-2 feeder material may be more FAC resistant than that of the $\mathrm{W}-1$. It is well understood that the $\mathrm{Cr}$ plays a critical role in improving the FAC resistance of carbon steel, and that $\mathrm{Mo}$ and $\mathrm{Cu}$ play some role, not as critical as that of $\mathrm{Cr}$ [1]. It should be noted that the $\mathrm{W}-2 \sim 4$ feeder contains more $\mathrm{Cr}$ than the W-1 feeder. No differences were noted among the Mo and $\mathrm{Cu}$ contents. The $\mathrm{Cr}$ contents in each feeder are compared among the four units, with data shown in Table 3. The chromium is not added intentionally to the feeder steel, but traces of chromium are found and may be considered as impurities. $\mathrm{Cr}$ content is recorded at $0.02 \%$ consistently for all channels of the $\mathrm{W}-1$ feeders. It may be a reasonable suspicion to say that the $0.02 \%$ may be a rough estimation from the detection limit rather than a precisely measured value. The average $\mathrm{Cr}$ content is $0.051 \%$, with the minimum at $0.030 \%$ for the $\mathrm{W}-2$ feeders. The average $\mathrm{Cr}$ content of the $\mathrm{W}-3$ and 4 is slightly less than that of the W-2 while maintaining the same minimum, 0.03. It is rather surprising that the very small difference of chromium content reduced the thinning rate to lower than half. It is generally understood that a small amount of chromium reduces FAC significantly. 1\% chromium content causes FAC to practically vanish, and contents as low as $0.1 \%$ may reduce FAC significantly under single water flow [1]. It is believed that the quantitative prediction of the effect of chromium contents reducing FAC is not simple when the chromium content is very low. The effectiveness may depend on conditions. It may be a reasonable assumption to say that low content of chromium is effective when the FAC is rather mild, while higher content of chromium may be required under conditions of severe thinning.

Z.H. Walker [5] reviewed the effect of chromium content on FAC of feeder based on experiments in research reactors and plant experiences. He suggested that $0.33 \%$

Table 3. Comparison of Chromium Contents of Reactor Outlet Feeders

\begin{tabular}{c|c|c|c|c}
\hline & $\mathrm{W}-1$ & $\mathrm{~W}-2$ & $\mathrm{~W}-3$ & $\mathrm{~W}-4$ \\
\hline average & 0.0200 & 0.0509 & 0.0355 & 0.0403 \\
\hline maximum & 0.0200 & 0.0900 & 0.0900 & 0.0600 \\
\hline minimum & 0.0200 & 0.0300 & 0.0300 & 0.0300 \\
\hline standard deviation & 0.0000 & 0.0126 & 0.0121 & 0.0042 \\
\hline number of feeder counted & 374 & 380 & 376 & 379 \\
\hline
\end{tabular}


chromium reduces FAC by $50 \sim 67 \%$ compared to very low chromium content, as low as $0.02 \%$. The CANDU specification for new feeders specifies the minimum chromium at $0.3 \%$. The substantially slower thinning rate of the W-2 feeder indicates that $\mathrm{Cr}$ content as low as $0.030 \%$ may be effective in reducing FAC. There is no possible explanation for the slower thinning of the W-2 feeder other than the chromium content.

\section{CONCLUSION}

$\mathrm{W}-1 \sim 4$ feeder inspection databases have been analyzed to draw the following conclusions.

1) The thinning rate is proportional to $Q V$ in each feeder.

2) The 2.5 inch feeder shows faster thinning and shorter remaining life than that of the 2 inch feeder, which can be understood by the thinning rate proportionate to $\mathrm{QV}$.

3) There seems to be no systematic difference between the thinning rate of the first bend and the second bend. The amount of inspection data, however, may not be extensive enough to make a firm conclusion.

4) W-2 feeder suffers far slower thinning than W-1 feeder, despite the faster coolant flow rate. It is believed that the small amount of chromium content in the W-2 feeder, averaging $0.051 \%$ and with a minimum of $0.030 \%$, is responsible for the better resistance of the steel to FAC

5) Knowledge based feeder inspection programs should be developed in order to focus on both the fastest thinning locations and the thinnest locations.

\section{ACKNOWLEDGEMENTS}

This paper is a result of a project sponsored by Korea Hydro and Nuclear Power.

\section{ACRONYMS}

ASME American Society of Mechanical Engineers

ASTM American Society of Testing Materials

CANDU Canadian Deuterium Unit (a registered trademark)
EFPY Effective Full Power Years

FAC Flow Accelerated Corrosion

PWR Pressurized Water Reactor

Q mass flow rate $(\mathrm{kg} / \mathrm{sec})$

$\mathrm{V} \quad$ flow velocity $(\mathrm{m} / \mathrm{sec})$

\section{REFERENCES}

[1] Bindi Chexal et al., Flow-Accelerated Corrosion in Power Plants, TR-106611-R1, Electric Power Research Institute, 1998

[2] Slade J P and Gendron T S, FAC and cracking of carbon steel piping in primary water-operating experience at the Point Lepreau Generating station, Proc. of the 12th International conf. on Environmental Degradation of materials in nuclear power systems-water reactors, Salt Lake City Utah USA, August 14-18, 2005, Ed. T R King, P J King and L Nelson, TMS 2005 p773-784.

[ 3 ] K.A. Burrill and E.L. Cheluget, Corrosion of CANDU Outlet Feeder Pipes, Proc. of the JAIF International Conference on Water Chemistry in Nuclear Power Plants, Kahiwaszaki, Japan, 1998, p699

[4 ] D.H. Lister et. al., The Accelerated Corrosion of CANDU Primary Piping, Proceedings of the JAIF International Conference on Water Chemistry in Nuclear Power Plants, Kahiwaszaki, Japan, 1998, p.442

[ 5 ] Z.H. Walker, Managing Flow Accelerated Corrosion in Carbon Steel Piping in Nuclear Plants, Proc. of ASME PVP: Pressure Vessels and Piping Conference, San Diego, USA, 2004

[6] O. De Bouvier, Effect of Redox Conditions on Flow Accelerated Corrosion: Influence of Hydrazine and Oxygen, Technical Report 1001768, Electric Power Research Institute, 2002

[ 7 ] F.H. Sweeton and C.F. Baes, J., The Solubility of Magnetite and Hydrolysis of Ferrous Ion in Aqueous Solutions at Elevated Temperatures, Chemical Thermodynamics 2, 479, 1970

[ 8 ] S.E. Ziemniak, M.E. Jones, and K.E.S. Combs, Magnetite Solubility and Phase Stability in Alkaline Media at Elevated Temperatures, J. Solution Chemistry, Vol.24, No. 9, 837, 1995

[9] R.L. Scheaffer and J.T. McClave, Probability and Statistics for Engineers, $3^{\text {rd }}$ edition, PWS-KENT Publishing Company, Boston MA USA, 1990 